\title{
MAPPING AND MODELING WEATHER AND CLIMATE WITH GIS
}

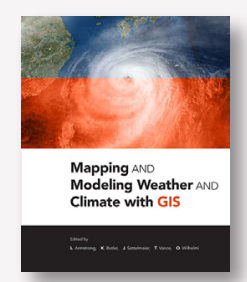

Edited by Lori Armstrong, Kevin Butler, Jack Settelmaier, Tiffany Vance, and Olga Wilhelmi

Esri Press, 2014

370 pages. $\$ 49.99$, hardcover.

ISBN: 978-1-58948-376-7

Review by: Mark Denil

Mapping and Modeling Weather and Climate with GIS is a topical title from Esri Press. There has been a significant increase in the frequency and intimacy of interactions between the modeling and GIS worlds. Modelers are looking to integrate more sophisticated "real world" inputs, and "real world" analysts and forecasters are taking more cognizance of modeled outputs. GIS systems, already quite flexible and adaptable to the exploration and study of a wide variety of geospatial phenomena, are a logical platform for hosting this nexus, as Esri has been letting everyone know via their serious expansion of support for the netCDF data format, support for the Pandas software library for Python, and now with this Esri Press book.

One prominent feature of many modeler/GISer interactions has been a profound cognitive and linguistic disconnection between practitioners in the respective realms. Some tenets built into the assumptions of operatives on one side of the partnership may simply not enter the consciousness or calculations of those on the other, and vice-versa. For example, just because a certain place on the modeled earth can be described with latitude and longitude values does not mean that the model operates "exclusively in a lat/long coordinate space." At the same time, the lat/long coordinates of a place may change dramatically if one assumes a different size and shape for the Earth (if one assumes it is, say, a perfect sphere instead of a spheroid), so it is important to define those parameters and share them with one's partners. Currently, a conscientious participant in one of these modeler/GISer exchanges must expend a good deal of effort (and diplomacy) to discover where the subtle and not-so-subtle dissonances lie, and to try to ease the streams into confluence.

This is where Mapping and Modeling Weather and Climate with GIS comes in. Strategically, the book tries to situate itself between the solitudes, and to supply grounds for bridging the divides.

Thirty-six individual authors contributed, in a variety of combinations, to the twenty-three chapters in this book. More than half of the authors are connected to US federal agencies, principally the National Oceanic and Atmospheric Administration (NOAA), but there are participants from academic, commercial, and military outfits as well. Almost all seem to be of the "GIS-aware modeling community," as opposed to the reverse. Three Esri folks contribute to six chapters between them, with the most prolific being a volume editor as well.

There is a lot of stuff in this book. The chapters are grouped into logical sections, which helps tremendously in navigation. The section titles- "Representations of atmospheric phenomena", "Observations," "Models," "Integrated analyses of models and observations," "Web services," and "Tools and resources" - demonstrate the sweep of topics covered to one degree or another. Reading Mapping and Modeling Weather and Climate with GIS cover to cover is, I can attest, a long row to hoe; but it was likely not intended to be read that way. Each chapter is autonomous, and stands alone with neither prerequisite nor, necessarily, connection to any other chapter; this is clearly intentional.

Intentional, too, is the general approach and level of address adopted in each chapter: this book is a tool to build mutual understanding, not to further developments in either community. I came out of reading it seeing two main things: how to start to present my activities and concerns so as to be understood by members of a community with similar interests but a very different approach and heritage, and how to begin to interpret what I get back from them in return. File formats are only one small part of this equation, and although they are covered, too, it seems to me that the book's value is more, well, anthropological. Esri puts out a lot of these "industry" books; most seem aimed at selling GIS to the industry. This one seems aimed at bringing two juggernauts together without collision.

That said, Mapping and Modeling Weather and Climate with GIS is not without shortcomings and faults, and the story 
of the Curate's Egg comes frequently to mind while reading it. In the story, a young curate was breakfasting with his bishop, when the superior remarked that the youngster had been given a spoiled egg. The curate, embarrassed by the fuss, continued to eat the bad egg while assuring his bishop that "parts of it are excellent." Luckily, this volume is more compartmentalized than is usual with eggs.

Blessedly few of the chapters read like $\mathrm{Arc} U_{\text {ser }}$ magazine reprints. Many of the authors, however, are clearly not experienced technical writers (as the level of writing in most "scientific" periodicals demonstrates is not uncommon in the field), so a good deal of some chapters are a good deal less clear than they might have been. For example, there seems to be a widespread misunderstanding of the concept of paragraph. Webster's dictionary (1944) defines it as "A distinct section or subdivision of a discourse, chapter, or writing, whether of one or many sentences, that forms a rhetorical unit as dealing with a particular point of the subject, or as comprising the words of a distinct speaker, etc." By contrast, in some of this book's chapters, paragraphs are employed simply as random breaks in the text.

It is worse than that, though. My review copy is filled with penciled corrections, excisions, and rearrangements of material, and not a few question marks. Sadly, some of the most potentially useful chapters, particularly Chapter 2, "Meteorological data in a geodatabase," are almost incoherent. The two authors of Chapter 2 do not so much perform a deep dive into UML and the International $\mathrm{H} 2 \mathrm{O}$
Project (IHOP) database structure as to smack into it fulltilt boogie: the results are awkward, confusing, and downright gory.

One should also say something about the standard Esri Press book layout; in particular, the tremendously long text lines used for body text. These lines are just too long for comfortable reading. Standard good practice tells us that "... even with generous leading, a line that averages more than 75 or 80 characters is likely to be too long for continuous reading" (Bringhurst 2002, 27). Standard Esri Press text lines average about 90 characters. Moving either to a wider page fly space (and narrower text block) or to two columns (maybe a less happy solution) would make reading one of these books rather less of a slog.

So, to wrap up: Mapping and Modeling Weather and Climate with GIS is a good stab at filling a big need. It is not without problems, but what in this vale of tears is not? If your office works with weather and climate modelers, this book should be there too.

\section{REFERENCES}

Bringhurst, Robert. 2002. The Elements of Typographic

Style, Version 2.5. Vancouver: Hartley and Marks.

Webster's New International Dictionary of the English

Language, 2nd Edition. 1944. Springfield, Mass: G\&C

Merriam.

\section{AMERICAN CAPITALS: A HISTORICAL GEOGRAPHY}

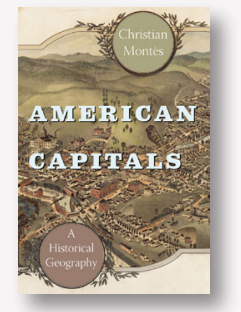

by Christian Montès

University of Chicago Press, 2014

394 pages. \$19.95, softcover.

ISBN: 978-0-226-08048-2

Review by: Russell S. Kirby, University of South Florida

As a peripatetic late twentieth- and early twenty-first-century academic, born to an academic family, my early life and later career led to residence in many US states, and I have had the good fortune to have lived in both large and smaller cities, some of which were state capitals. My professional and personal travels have led to visits to many other state capitals as well. Still, it never occurred to me that the subject of state capitals might be worthy of a book-length historical geographic treatment.

This monograph, published as a University of Chicago Research Paper, shows that it indeed might. In his study, Christian Montès thoroughly explores the topic of the capitals of the states (and territories) of the United States. It could perhaps be said that Montès examines his subject from every conceivable perspective: from the relative locations of capitals within states, to change in location of state capitals over time, to their very names, while also examining a wide array of other questions along the way. 